\title{
Continuous Glucose Monitoring for Evaluation of Glycemic Excursions after Gastric Bypass
}

\author{
Florencia Halperin, ${ }^{1,2,3}$ Mary Elizabeth Patti, ${ }^{2,3}$ Megan Skow, ${ }^{2}$ Muhammad Bajwa, ${ }^{2}$ \\ and Allison B. Goldfine ${ }^{1,2,3}$
}

${ }^{1}$ Brigham and Women's Hospital, Boston 02115, MA, USA
${ }^{2}$ Joslin Diabetes Center, Boston, MA 02215, USA
${ }^{3}$ Harvard Medical School, Boston 02115, MA, USA

Correspondence should be addressed to Allison B. Goldfine, allison.goldfine@joslin.harvard.edu

Received 4 November 2010; Accepted 13 January 2011

Academic Editor: Eric Doucet

Copyright (C) 2011 Florencia Halperin et al. This is an open access article distributed under the Creative Commons Attribution License, which permits unrestricted use, distribution, and reproduction in any medium, provided the original work is properly cited.

\begin{abstract}
Background. Hyperinsulinemic hypoglycemia with neuroglycopenia is a rare complication of Roux-en-Y gastric bypass (RYGB). We hypothesized that continuous glucose monitoring (CGM) would be useful to characterize glycemic variability after RYGB. Methods. CGM and mixed meal tolerance testing (MMTT) were performed on sixteen post-RYGB subjects, ten with a history of neuroglycopenia on medical treatment and six asymptomatic controls. Results. 9 of 10 subjects with neuroglycopenia developed hypoglycemia defined by glucose $<70 \mathrm{mg} / \mathrm{dL}$ on CGM, and 3 of 9 on MMTT. In asymptomatic subjects, 3 of 6 had asymptomatic hypoglycemia during CGM, and 3 of 5 on MMTT. Therefore, the sensitivity and specificity to detect clinically significant hypoglycemia was $90 \%$ and $50 \%$ for CGM and 33\% and $40 \%$ for MMTT. Conclusions. Asymptomatic hypoglycemia after RYGB is more frequent than commonly recognized. For clinicians evaluating patients for postbypass neuroglycopenia, CGM may be a valuable diagnostic tool.
\end{abstract}

\section{Introduction}

Roux-en-Y gastric bypass (RYGB) results in substantial weight loss, averaging $30-40 \mathrm{~kg}$ (about $60 \%$ excess weight) [1] which can be sustained over 10-15 years [2]. RYGB also results in improvement of multiple comorbidities associated with obesity. About $75 \%$ of patients with type 2 diabetes who undergo RYGB are able to discontinue all diabetesrelated medications and maintain normoglycemia [3-6]. Dyslipidemia improves or resolves in $70 \%-95 \%$ of surgically treated patients and hypertension in $87 \%-95 \%$ [5]. In addition, studies suggest that mortality may be decreased by as much as $40 \%[2,7]$.

Long-term complications of RYGB remain incompletely understood. Known complications of the operation include anemia, vitamin and mineral deficiencies, peripheral neuropathy, short term surgical complications such as thromboembolism and small bowel obstruction, as well as dumping syndrome, anatomic complications such as herniation, ulceration or strictures, and multiple others [8].
Additionally, rarely patients may develop hyperinsulinemic hypoglycemia with neuroglycopenia that typically presents 2-5 years postoperatively [9-11]. The pathophysiology of postgastric bypass hyperinsulinemic hypoglycemia is not well understood. Hypoglycemia usually occurs two to three hours after meals [12]. Patients exhibit exaggerated incretin and insulin responses after food intake [13-15]. Alterations in other gut hormones, including peptide YY, ghrelin, and leptin, have also been implicated in glycemic patterns following RYGB [14, 16-19]. Pancreatic histology from the subset of severely affected patients requiring partial pancreatectomy has been consistent with nesidioblastosis in some studies, with $\beta$-cells demonstrating increased nuclear diameter, and increases in both large and small islets, some of irregular shape and many clustering near ducts $[9,10]$. However, it remains uncertain whether there is true islet hyperplasia or increased $\beta$-cell mass in this syndrome, as control samples matched for obesity and major weight loss are not readily available $[12,20$, 21]. 
The frequency of severe hypoglycemia following RYGB and potentially related complications requiring hospitalization, such as confusion, syncope, seizures, and/or accidental death, is conservatively estimated from Swedish national data to be about $0.2 \%$. Although these data underestimate the risk of more mild hypoglycemia not requiring hospital evaluation, the relative risk of these severe complications is two- to sevenfold higher after bypass than in nonoperated persons [22]. Furthermore, glucose variability may be high following gastric bypass $[15,23]$.

In this study, we used continuous glucose monitoring (CGM) technology and mixed meal tolerance testing (MMTT) to evaluate patients who presented with clinically significant neuroglycopenia following RYGB in whom medical management had been initiated, as compared to patients who have no symptoms of hypoglycemia following gastric bypass. We hypothesized that CGM would be a useful clinical tool in this population and that glycemic variability would be better evaluated under real-life conditions at home than by a MMTT in clinical research testing conditions.

\section{Materials and Methods}

The Internal Review Board of Joslin Diabetes Center approved this study. All subjects provided written informed consent. Subjects in the symptomatic group were referred for management of postgastric bypass neuroglycopenia, defined as documented hypoglycemia associated with altered mental status or level of consciousness, with or without seizure, requiring assistance of others. Because of the severity of their condition, all of the symptomatic patients had already been counseled regarding medical nutritional therapy, with emphasis on controlled portions of low glycemic index carbohydrates. In addition, at the time of study, 8 of 10 subjects in the symptomatic group were on $\alpha$-glucosidase inhibitor therapy to reduce or delay dietary carbohydrate absorption to decrease the frequency of debilitating hypoglycemic episodes. One patient was on octreotide and one on diazoxide. This group is therefore referred to as the treated symptomatic group (TX-SX). Only one patient in this group had diabetes preoperatively; this individual was taking no diabetes medications and was without hyperglycemia at the time of study. Subjects did not have a diagnosis of hypoglycemia prior to surgery.

The control group comprised 6 women who had undergone laparoscopic RYGB who denied any current or previous symptoms characteristic of hypoglycemia, even upon careful questioning by study investigators (referred to as asymptomatic for hypoglycemia (ASX)). These subjects were recruited through advertisements in bariatric surgical clinics and local newspapers. None had known diabetes prior to RYGB. All subjects were weight stable, were similar in duration following RYGB to the TX-SX study group, and were otherwise in good health.

2.1. Mixed Meal Tolerance Testing. Octreotide and diazoxide were held for 24 hours prior to MMTT, and $\alpha$-glucosidase inhibitors were omitted on the morning of study. Given that subjects in the TX-SX group had severe hypoglycemic episodes, it was felt that a longer washout period would not be safe. Height and weight were measured using a wall-mounted stadiometer (Holtain Ltd., Crymych, UK) and electronic scale (model 0501; Acme Scale Co., San Leandro, CA). Subjects were studied following a 10-12 hour overnight fast. Fasting blood samples were obtained before a liquid mixed meal (Ensure, $9 \mathrm{~g}$ protein, $40 \mathrm{~g}$ carbohydrate, $6 \mathrm{~g}$ fat, $240 \mathrm{~mL}$; Abbott Laboratories, Abbott Park, IL) with subsequent samples collected at 10, 20, 30, 60, and 120 minutes for measurement of glucose, insulin, and C-peptide.

During the MMTT, glucose was measured by glucose oxidation, fasting cholesterol and high-density lipoprotein (HDL) by cholesterol esterase assay, triglycerides via hydrolysis to glycerol, and hemoglobin Alc by HPLC (Tosoh 2.2; Tosoh Bioscience, San Francisco, CA). Insulin and C-peptide were measured in duplicate serum samples by radioimmunoassay (Diagnostic Systems Laboratories, Webster, TX).

2.2. Continuous Glucose Monitoring. Within one month after completion of the MMTT, study participants underwent placement of a continuous glucose monitor (Medtronic Minimed iPro, Medtronic, Northridge, CA). A study nurse inserted the CGM according to manufacturer directions and provided participants with instructions regarding CGM maintenance and capillary blood glucose monitoring every 6 hours for CGM calibration. Participants wore the CGM for at least 72, and up to 120, continuous hours; during that time, they kept a log documenting capillary blood glucose results as well as symptoms experienced at any time. CGM data were analyzed with Minimed iPro software version 2.1A.

2.3. Statistical Analysis. Data are expressed as mean \pm standard error unless otherwise indicated. Calculation of sensitivity and specificity for CGM and MMTT was performed according to the following formulas: sensitivity $=$ number of true positives/(number of true positives + number of false negatives); specificity $=$ number of true negatives/(number of true negatives + number of false positives). A true positive was defined as a numerical value of hypoglycemia (glucose $<70 \mathrm{mg} / \mathrm{dL}$ ) during a test in a subject with the prior clinical occurrence of neuroglycopenia, as these patients (in the TX-SX group) had all had multiple episodes of welldocumented hypoglycemia associated with altered mental status requiring assistance of others. A false positive was defined as a numerical value of hypoglycemia during a test in a subject with no history of symptomatic hypoglycemia (ASX) and no symptoms of hypoglycemia during the test (as self-reported on symptom log during CGM and as assessed by a study nurse during MMTT).

Two-tailed Student's $t$-test, or Mann-Whitney nonparametric test if data were not normally distributed, was used to compare the results between groups. Repeated measures ANOVA was used to compare variables at several time points after a mixed meal. Statistical analysis was performed using StatView (SAS Institute, Inc., Cary, NC). Significance was set at $P<.05$. 
TABLE 1: Characteristics of study subjects.

\begin{tabular}{lcc}
\hline & $\begin{array}{c}\text { Gastric bypass with neuroglycopenia (TX-SX) } \\
(n=10)\end{array}$ & $\begin{array}{c}\text { Gastric bypass asymptomatic (ASX) } \\
(n=6)\end{array}$ \\
\hline Age (years) & $51 \pm 4$ & $52 \pm 5$ \\
Preoperative body mass index $\left(\mathrm{kg} / \mathrm{m}^{2}\right)$ & $50.1 \pm 2.5$ & $46.2 \pm 3.4$ \\
Body mass index at evaluation $\left(\mathrm{kg} / \mathrm{m}^{2}\right)$ & $29.8 \pm 1.9$ & $30.0 \pm 2.7$ \\
Magnitude of weight loss $(\mathrm{kg})$ & $53.0 \pm 8.8$ & $45.0 \pm 5.4$ \\
Postoperative duration (years) & $8.9 \pm 2.4$ & $5.3 \pm 0.9$ \\
Hemoglobin Alc (\%) & $5.7 \pm 0.1$ & $5.7 \pm 0.1$ \\
Total cholesterol (mg/dL) & $170.1 \pm 7.9$ & $173.5 \pm 8.4$ \\
Triglycerides (mg/dL) & $66.2 \pm 4.9$ & $72.5 \pm 5.5$ \\
LDL cholesterol (mg/dL) & $98.9 \pm 7.2$ & $93.0 \pm 10.1$ \\
HDL cholesterol (mg/dL) & $62.2 \pm 4.3$ & $73.8 \pm 8.8$ \\
Systolic blood pressure (mm Hg) & $118.1 \pm 4.7$ & $117.5 \pm 6.9$ \\
Diastolic blood pressure (mm Hg) & $67.1 \pm 2.1$ & $66.5 \pm 2.9$ \\
Dumping score & $64.7 \pm 18.7$ & $60.5 \pm 25.5$ \\
\hline
\end{tabular}

Characteristics presented as mean \pm standard error. There was no statistically significant difference in these variables between the two groups.

\section{Results and Discussion}

3.1. Results. Characteristics of the 16 subjects are summarized in Table 1. Subjects in the treated symptomatic (TX-SX) group, who had symptomatic neuroglycopenia after gastric bypass, were similar to those who remained asymptomatic (ASX) with respect to age, preoperative and current body mass index (BMI), magnitude of weight loss and duration of time since RYGB; the TX-SX and ASX group were also similar with respect to hemoglobin A1c, lipid levels and blood pressure at time of study (Table 1).

3.1.1. Mixed Meal Tolerance Test. Nine subjects in the TX-SX group and 5 subjects in the ASX group underwent MMTT; one subject in each group was unable to complete the test secondary to difficulties obtaining intravenous access. Fasting glucose was not different between the TX-SX and ASX group $(73 \pm 1$ versus $75 \pm 2 \mathrm{mg} / \mathrm{dL} ; P=.4)$. Over the entire 2 hours, the blood glucose levels were likewise not different between the two groups. The area under the curve (AUC) for glucose (0-120 minutes) (3399 \pm 695 versus $2285 \pm 78 \mathrm{mg} / \mathrm{dL} / \mathrm{min} ; P=.5)$ and repeated measures ANOVA comparing the glucose levels over 2 hours were not significantly different $(P=.2)$. However, at 120 minutes after meal, the ASX group had significantly lower blood glucose than the TX-SX group $(71 \pm 1$ versus $77 \pm 3 \mathrm{mg} / \mathrm{dL} ; P=.05)$.

Neither fasting insulin levels $(3.6 \pm 0.8$ versus $3.2 \pm$ $0.9 \mu \mathrm{U} / \mathrm{mL} ; P=.7)$ nor insulin AUC $(5478 \pm 867$ versus $4308 \pm 801 \mu \mathrm{U} / \mathrm{mL} / \mathrm{min} ; P=.5)$ during MMTT was different between the TX-SX and ASX groups. However, consistent with a hyperinsulinemic etiology of hypoglycemia, there was a trend towards greater insulin secretion in the TXSX group including HOMA-IS $(151 \pm 41$ versus $73 \pm 20$; $P=.16$ ) [24]. Insulin levels also tended to be higher in the TX-SX group at 30 and 60 minutes (time 30: $129 \pm 27$ versus $88 \pm 20 \mu \mathrm{U} / \mathrm{mL}, P=.30$; time $60: 25 \pm 5$ versus $15 \pm 4 \mu \mathrm{U} / \mathrm{mL}, P=.15)$, though these did not reach statistical significance. Similarly, fasting C-peptide levels, C-peptide AUC, and repeated measures ANOVA for all time points during the MMTT were also not different between the TX-SX and ASX groups (data not shown). There was also no difference in insulin resistance between the TX-SX and ASX (HOMA-IR: $0.65 \pm 0.13$ versus ASX $0.45 \pm 0.15 ; P=.16$ ) [24].

We also assessed whether dumping syndrome physiology was contributing to symptoms during the MMTT [25]. However, we identified no difference in the average dumping scores of the two groups ( $65 \pm 19$ versus $60 \pm 25, P=.8$ ).

3.1.2. Continuous Glucose Monitoring. All subjects wore CGM for a minimum of 3 days. The TX-SX group tended to wear the device for longer and as a result had a higher number of average sensor values (interstitial glucose readings) $(1099 \pm 75$ versus $721 \pm 5 ; P=.01)$. As a result, all data for glycemic excursions are expressed as number of events of, or minutes spent in, hypo- or hyperglycemia per day (24-hour period of sensor recordings). Data are also expressed as percent time per day within a given glycemic range [26].

The average interstitial glucose was similar between the two groups (TX-SX: $104 \pm 3$ versus ASX $101 \pm 3 \mathrm{mg} / \mathrm{dL}$; $P=1.0)$. The TX-SX group had more total abnormal glucose excursions compared to the ASX group $(8.5 \pm 2.1$ versus $3.8 \pm 2.3 ; P=.05)$, that is, including both hypoglycemic $(<70 \mathrm{mg} / \mathrm{dL})$ and hyperglycemic $(>180 \mathrm{mg} / \mathrm{dL})$ glucose excursions.

Hypoglycemia. CGM data were analyzed to determine frequency of hypoglycemia. Excursions during which interstitial glucose fell below $70 \mathrm{mg} / \mathrm{dL}$ per day occurred twofold more frequently in the symptomatic group, though this did not reach statistical significance $(1.45 \pm 0.42$ versus $0.78 \pm 0.44$; $P=.1$ ). Similar patterns were observed when expressed as minutes per day or percent time per day spent in 
hypoglycemia $(<70 \mathrm{mg} / \mathrm{dL})$, with hypoglycemia two times more frequent in the TX-SX group (TX-SX $63 \pm 23$ versus $34 \pm 22$ min per day, $P=.28 ; 5.5 \pm 1.9$ versus $3.1 \pm 2.0 \%$ time per day, $P=.23$ ). Excursions $<60 \mathrm{mg} / \mathrm{dL}$ were also not significantly different in the TX-SX and ASX groups (TX-SX $30 \pm 14$ versus $18 \pm 12$ min per day, $P=.45 ; 2.6 \pm 1.2$ versus $3.1 \pm 1.6 \%$ time per day, $P=.39$ ). The average minimum interstitial glucose values were not significantly lower in the TX-SX group ( $58 \pm 5$ versus $64 \pm 7 \mathrm{mg} / \mathrm{dL} ; P=.46$ ).

Hyperglycemia. The maximum interstitial glucose value was significantly higher in the TX-SX group compared to the ASX group $(213 \pm 13$ versus $167 \pm 13 \mathrm{mg} / \mathrm{dL} ; P=.03)$. Although the TX-SX group spent more minutes per day and more percent time per day in hyperglycemia $(>180 \mathrm{mg} / \mathrm{dL})$, the difference was not statistically significant (TX-SX $11 \pm 3$ versus $9 \pm 6$ min per day, $P=.59 ; 1.0 \pm 0.3$ versus $0.6 \pm 0.4 \%$ time per day, $P=.30$ ).

3.1.3. Sensitivity and Specificity of Tests. Nine of 10 (90\%) subjects who had experienced documented neuroglycopenia and were actively treated for post-bypass hypoglycemia syndrome developed hypoglycemia on CGM whereas only 3 of $9(33 \%)$ demonstrated hypoglycemia on MMTT. In comparison, 3 of 6 asymptomatic subjects (50\%) had hypoglycemia $(<70 \mathrm{mg} / \mathrm{dL})$ on CGM, and even more, 3 of $5(60 \%)$, on MMTT. This corresponds to a sensitivity of $90 \%$ and specificity of $50 \%$ for CGM, and $33 \%$ and $40 \%$ for MMTT (Table 2).

\section{Discussion}

In this study, continuous glucose monitoring technology is compared to standardized mixed meal tolerance testing in a cohort of patients with a history of postgastric bypass neuroglycopenia and an asymptomatic postgastric bypass group. Patients with history of neuroglycopenia were referred for medical evaluation after initiation of therapeutic interventions. Our data suggest that CGM may be a better tool for the diagnosis of glycemic variability in patients with clinically significant post-bypass hypoglycemia than MMTT, even in treated patients. The diagnosis of postgastric bypass hypoglycemia can be challenging to make, as hypoglycemic symptoms are nonspecific and can be difficult to distinguish from dumping syndrome [23]. There are currently no published recommendations to guide clinicians in the evaluation of patients suspected of having this syndrome. In our study, CGM had a sensitivity of $90 \%$ and specificity of 50\%, compared to only $33 \%$ and $40 \%$ for MMTT, to distinguish patients with history of neuroglycopenia. The difference between testings may be because MMTT captures only one meal compared to many with CGM. Furthermore, the meal size, nutrient composition, and concurrent activity level, which are likely different in real life compared to research conditions, could play a role in the magnitude of postprandial hypoglycemia. Similarly, differences in counterregulatory or stress hormones, such as cortisol or catecholamines, could also attenuate postprandial hypoglycemia in the research setting. Until the reason for the difference in testing results can be better elucidated or additional diagnostic options are available, CGM appears to be a potentially valuable diagnostic test.

Measurement of interstitial glucose by CGM has previously been validated for the detection of hypoglycemia in other patient populations [27] and comparison of CGM to corresponding blood glucose levels demonstrated high accuracy during both euglycemia and hypoglycemia $[26,28]$. A prior case report [23] found CGM useful to document hypoglycemia and response to treatment in a single postbypass patient with type 2 diabetes. Vidal et al. [15] also used CGM in post-bypass patients, but subjects with symptomatic hypoglycemic episodes were specifically excluded. Our data therefore extend the current literature on glycemic excursions in response to gastric bypass, in particular in those who develop the rare but well-established syndrome of postbypass neuroglycemia, which can result in life-threatening adverse events.

The data presented in this paper also provide additional insight into the effects of gastric bypass on glucose homeostasis. Patients who have had neuroglycopenia after gastric bypass experience an average of about 63 minutes per day with an interstitial glucose below $70 \mathrm{mg} / \mathrm{dL}$ and 30 minutes per day with an interstitial glucose below $60 \mathrm{mg} / \mathrm{dL}$. Although interstitial glucose in the hypoglycemic range was increased about twofold in the TX-SX group, these findings were not statistically significant. This may be related to the fact that most subjects had such severe hypoglycemic episodes that treatment had already been initiated at the time of study and could not safely be withheld during CGM. It may have also been a result of small sample size, and alternatively, or perhaps additionally, statistical significance may not have been achieved because of the unexpectedly high rates of hypoglycemia detected on CGM in the asymptomatic group.

Indeed, even in those without symptoms of hypoglycemia after RYGB, low glucose levels may occur more frequently than commonly recognized. In our series, 3 out of $6(50 \%)$ completely asymptomatic individuals had an interstitial glucose below $70 \mathrm{mg} / \mathrm{dL} ; 2$ out of $6(33 \%)$ had a value below $60 \mathrm{mg} / \mathrm{dL}$ (and as low as $40 \mathrm{mg} / \mathrm{dL}$ ). This is consistent with our prior report that one-third of asymptomatic patients developed hypoglycemia (plasma glucose $<60 \mathrm{mg} / \mathrm{dL}$ ) after MMTT, but higher than the $12.5 \%$ of asymptomatic patients reported to have had hypoglycemia (glucose $<50 \mathrm{mg} / \mathrm{dl}$ ) on CGM by Vidal et al. [15]. The differences may be related to different threshold definitions of hypoglycemia, small sample sizes in all studies, and methodology used for evaluation. Given that a disproportionate increase in death rates due to accidents has been reported after gastric bypass [7], finding significant rates of hypoglycemia in symptom-free post-bypass subjects raises the question about whether such accidents might be related to unrecognized hypoglycemia. Furthermore, why at similar glucose concentration some patients experience symptoms while others do not is not understood; adaptive mechanisms to hypoglycemia or susceptibility to neuroglycopenia may vary between individuals after gastric bypass, but these potential differences merit further study. 
TABLE 2: Results from continuous glucose monitoring and mixed meal tolerance testing on post-gastric bypass subjects with documented episodes of neuroglycopenia on medical treatment (TX-SX) or without any symptoms of hypoglycemia (ASX).

\begin{tabular}{|c|c|c|c|}
\hline & $\begin{array}{c}\text { Gastric bypass with } \\
\text { neuroglycopenia } \\
\text { (TX-SX) }\end{array}$ & $\begin{array}{c}\text { Gastric bypass } \\
\text { asymptomatic } \\
\text { (ASX) }\end{array}$ & $P$ value \\
\hline \multicolumn{4}{|l|}{$\overline{C G M}$} \\
\hline Average interstitial glucose (mg/dL) & $104 \pm 3$ & $101 \pm 3$ & $P=1.00$ \\
\hline Average number of daily excursions $<70 \mathrm{mg} / \mathrm{dL}$ & $1.45 \pm 0.42$ & $0.78 \pm 0.44$ & $P=.10$ \\
\hline Minutes/day glucose $<70 \mathrm{mg} / \mathrm{dL}$ & $63 \pm 23$ & $34 \pm 22$ & $P=.28$ \\
\hline Minutes/day glucose $<60 \mathrm{mg} / \mathrm{dL}$ & $30 \pm 14$ & $18 \pm 12$ & $P=.45$ \\
\hline Average minimum glucose (mg/dL) & $58 \pm 5$ & $64 \pm 7$ & $P=.46$ \\
\hline Average maximum glucose (mg/dL) & $213 \pm 13$ & $167 \pm 13$ & $P=.03$ \\
\hline Minutes/day glucose $>180 \mathrm{mg} / \mathrm{dL}$ & $11 \pm 3$ & $9 \pm 6$ & $P=.59$ \\
\hline $\begin{array}{l}\text { Total abnormal glucose excursions (hypoglycemic }<70 \mathrm{mg} / \mathrm{dL} \text {, plus } \\
\text { hyperglycemic }>180 \mathrm{mg} / \mathrm{dL} \text { ) }\end{array}$ & $8.5 \pm 2.1$ & $3.8 \pm 2.3$ & $P=.05$ \\
\hline \multicolumn{4}{|l|}{ MMTT } \\
\hline Fasting blood glucose (mg/dL) & $73 \pm 1$ & $75 \pm 2$ & $P=.40$ \\
\hline Glucose area under curve (0-120 $\mathrm{mins})(\mathrm{mg} / \mathrm{dL} / \mathrm{min})$ & $3399 \pm 695$ & $2285 \pm 782$ & $P=.50$ \\
\hline Glucose at time $120 \mathrm{mins}(\mathrm{mg} / \mathrm{dL})$ & $71 \pm 1$ & $77 \pm 3$ & $P=.05$ \\
\hline Fasting insulin $(\mu \mathrm{U} / \mathrm{mL})$ & $3.6 \pm 0.8$ & $3.2 \pm 0.9$ & $P=.70$ \\
\hline Insulin at time $30 \mathrm{mins}(\mu \mathrm{U} / \mathrm{mL})$ & $129 \pm 27$ & $88 \pm 20$ & $P=.30$ \\
\hline Insulin at time $60 \operatorname{mins}(\mu \mathrm{U} / \mathrm{mL})$ & $25 \pm 5$ & $15 \pm 4$ & $P=.15$ \\
\hline \multicolumn{4}{|l|}{ Sensitivity* } \\
\hline CGM & \multicolumn{3}{|c|}{$9 / 10(90 \%)$} \\
\hline MMTT & \multicolumn{3}{|c|}{$3 / 9(33 \%)$} \\
\hline \multicolumn{4}{|l|}{ Specificity** } \\
\hline CGM & \multicolumn{3}{|c|}{$3 / 6(50 \%)$} \\
\hline MMTT & \multicolumn{3}{|c|}{$2 / 5(40 \%)$} \\
\hline
\end{tabular}

Data presented as mean \pm standard error. CGM: continuous glucose monitoring; MMTT: mixed meal tolerance testing.

* Sensitivity = number of true positives/(number of true positives + number of false negatives).

** Specificity $=$ number of true negatives $/$ (number of true negatives + number of false positives). True positive is defined as a numerical value of hypoglycemia (glucose $<70 \mathrm{mg} / \mathrm{dL}$ ) during a test in a subject with the prior clinical occurrence of neuroglycopenia (TX-SX group). A false positive is defined as a numerical value of hypoglycemia during a test in a subject without the presence or history of symptoms.

Our CGM data also show that patients with prior neuroglycopenia following gastric bypass demonstrate higher glycemic peaks when compared with asymptomatic postbypass persons (maximum interstitial glucose value 212 versus $167 \mathrm{mg} / \mathrm{dL} ; P=.03$ ). Although we cannot directly address the causal factors potentially responsible for this pattern, this could be consistent with a rapid increase in plasma glucose after oral intake potentially leading to a high insulin peak and consequent hypoglycemia, as has previously been proposed [29]. However, our MMTT results did not support this, as post-MMTT glycemic response was not higher in the TX-SX than the ASX group, and prior published data addressing this question have not been consistent $[13,29]$. We previously reported that glucose levels during the 30 minutes after MMTT were lower in a group of subjects that had experienced neuroglycopenia (but were treatment naive) compared to post-RYGB asymptomatic controls [13]. In contrast, Kim et al. [29] found that 30minute glucose values after a $75 \mathrm{~g}$ oral glucose tolerance test were higher in a symptomatic hypoglycemia compared to an asymptomatic post-bypass group. While differences in these findings may relate to differences in the type and carbohydrate content of the test stimulus, it is interesting that both studies did find that time-to-peak glucose was shorter in the symptomatic patients. More studies are clearly needed to better characterize postprandial glucose, insulin, and other metabolically important hormone dynamics in patients who develop significant hypoglycemia after bariatric surgery.

Our main study limitation is the small sample size. However, given that neuroglycopenia after gastric bypass is a relatively rare phenomenon, the size of the TX-SX cohort assembled for this study is substantial. Furthermore, previous medical management for neuroglycopenia could attenuate glycemic variability and affect conclusions.

\section{Conclusions}

Asymptomatic hypoglycemia is more frequent than commonly recognized in post-bypass patients. The clinical importance of these events, and why at similar glucose levels some patients experience hypoglycemic symptoms while others do not remains incompletely understood. 
The underlying pathophysiology of the post-bypass hypoglycemia syndrome, including post-prandial glucose and hormonal dynamics, needs to be better characterized and warrants continued investigation. For clinicians evaluating patients for the rare but potentially life-threatening complication of neuroglycopenia after gastric bypass surgery, CGM may be a valuable diagnostic test.

\section{Acknowledgments}

The authors thank Medtronic for the use of the iPro continuous glucose monitoring materials for this investigatorinitiated investigation. They acknowledge support of the Joslin Clinical Research Center and thank its philanthropic donors. This research was supported by National Institutes of Health (NIH) Grant DERC P30-DK-36836 (Specialized Assay Core, Joslin Diabetes Center) and NIH 1RC1DK086918, as well as the KL2/MeRIT program of Harvard Catalyst The Harvard Clinical and Translational Science Center (Award no. UL1 RR 025758 and financial contributions from Harvard University and its affiliated academic health care centers) (the first author).

\section{References}

[1] H. Buchwald, R. Estok, K. Fahrbach et al., "Weight and type 2 diabetes after bariatric surgery: systematic review and metaanalysis," American Journal of Medicine, vol. 122, no. 3, pp. 248-256.e5, 2009.

[2] L. Sjöström, K. Narbro, C. D. Sjöström et al., "Effects of bariatric surgery on mortality in Swedish obese subjects," New England Journal of Medicine, vol. 357, no. 8, pp. 741-752, 2007.

[3] P. R. Schauer, B. Burguera, S. Ikramuddin et al., "Effect of laparoscopic Roux-en Y gastric bypass on type 2 diabetes mellitus," Annals of Surgery, vol. 238, no. 4, pp. 467-485, 2003.

[4] E. V. Polyzogopoulou, F. Kalfarentzos, A. G. Vagenakis, and T. K. Alexandrides, "Restoration of euglycemia and normal acute insulin response to glucose in obese subjects with type 2 diabetes following bariatric surgery," Diabetes, vol. 52, no. 5, pp. 1098-1103, 2003.

[5] M. L. Vetter, S. Cardillo, M. R. Rickels, and N. Iqbal, "Narrative review: effect of bariatric surgery on type 2 diabetes mellitus," Annals of Internal Medicine, vol. 150, no. 2, pp. 94-103, 2009.

[6] M. A. Maggard, L. R. Shugarman, M. Suttorp et al., "Metaanalysis: surgical treatment of obesity," Annals of Internal Medicine, vol. 142, no. 7, pp. 547-559, 2005.

[7] T. D. Adams, R. E. Gress, S. C. Smith et al., "Long-term mortality after gastric bypass surgery," New England Journal of Medicine, vol. 357, no. 8, pp. 753-761, 2007.

[8] J. H. Pinkney, A. B. Johnson, and E. A. M. Gale, "The big fat bariatric bandwagon," Diabetologia, vol. 53, pp. 1815-1822, 2010.

[9] M. E. Patti, G. McMahon, E. C. Mun et al., "Severe hypoglycaemia post-gastric bypass requiring partial pancreatectomy: evidence for inappropriate insulin secretion and pancreatic islet hyperplasia," Diabetologia, vol. 48, no. 11, pp. 2236-2240, 2005.

[10] G. J. Service, G. B. Thompson, F. J. Service, J. C. Andrews, M. L. Collazo-Clavell, and R. V. Lloyd, "Hyperinsulinemic hypoglycemia with nesidioblastosis after gastric-bypass surgery," New England Journal of Medicine, vol. 353, no. 3, pp. 249-254, 2005.
[11] K. Z'graggen, A. Guweidhi, R. Steffen et al., "Severe recurrent hypoglycemia after gastric bypass surgery," Obesity Surgery, vol. 18, no. 8, pp. 981-988, 2008.

[12] M. E. Patti and A. B. Goldfine, "Hypoglycaemia following gastric bypass surgery-diabetes remission in the extreme?" Diabetologia, vol. 53, no. 11, pp. 2276-2279, 2010.

[13] A. B. Goldfine, E. C. Mun, E. Devine et al., "Patients with neuroglycopenia after gastric bypass surgery have exaggerated incretin and insulin secretory responses to a mixed meal," Journal of Clinical Endocrinology and Metabolism, vol. 92, no. 12, pp. 4678-4685, 2007.

[14] B. Laferrère, S. Heshka, K. Wang et al., "Incretin levels and effect are markedly enhanced 1 month after Roux-en-Y gastric bypass surgery in obese patients with type 2 diabetes," Diabetes Care, vol. 30, no. 7, pp. 1709-1716, 2007.

[15] J. Vidal, J. Nicolau, F. Romero et al., "Long-term effects of roux-en-y gastric bypass surgery on plasma glucagon-like peptide-1 and islet function in morbidly obese subjects," Journal of Clinical Endocrinology and Metabolism, vol. 94, no. 3, pp. 884-891, 2009.

[16] D. E. Cummings, D. S. Weigle, R. S. Frayo et al., "Plasma ghrelin levels after diet-induced weight loss or gastric bypass surgery," New England Journal of Medicine, vol. 346, no. 21, pp. 1623-1630, 2002.

[17] C. M. Borg, C. W. Le Roux, M. A. Ghatei, S. R. Bloom, A. G. Patel, and S. J. B. Aylwin, "Progressive rise in gut hormone levels after Roux-en-Y gastric bypass suggests gut adaptation and explains altered satiety," British Journal of Surgery, vol. 93, no. 2, pp. 210-215, 2006.

[18] J. Korner, M. Bessler, W. Inabnet, C. Taveras, and J. J. Holst, "Exaggerated glucagon-like peptide-1 and blunted glucosedependent insulinotropic peptide secretion are associated with Roux-en-Y gastric bypass but not adjustable gastric banding," Surgery for Obesity and Related Diseases, vol. 3, no. 6, pp. 597601, 2007.

[19] R. Morínigo, V. Moizé, M. Musri et al., "Glucagon-like peptide-1, peptide YY, hunger, and satiety after gastric bypass surgery in morbidly obese subjects," Journal of Clinical Endocrinology and Metabolism, vol. 91, no. 5, pp. 1735-1740, 2006.

[20] T. E. Clancy, F. D. Moore Jr., and M. J. Zinner, "Postgastric bypass hyperinsulinism with nesidioblastosis: subtotal or total pancreatectomy may be needed to prevent recurrent hypoglycemia," Journal of Gastrointestinal Surgery, vol. 10, no. 8, pp. 1116-1119, 2006.

[21] J. J. Meier, A. E. Butler, R. Galasso, and P. C. Butler, "Hyperinsulinemic hypoglycemia after gastric bypass surgery is not accompanied by islet hyperplasia or increased $\beta$-cell turnover," Diabetes Care, vol. 29, no. 7, pp. 1554-1559, 2006.

[22] R. Marsk, E. Jonas, F. Rasmussen, and E. Näslund, "Nationwide cohort study of post-gastric bypass hypoglycaemia including 5,040 patients undergoing surgery for obesity in 1986-2006 in Sweden," Diabetologia, vol. 53, pp. 2307-2311, 2010.

[23] H. Hanaire, A. Dubet, M. E. Chauveau et al., "Usefulness of continuous glucose monitoring for the diagnosis of hypoglycemia after a gastric bypass in a patient previously treated for type 2 diabetes," Obesity Surgery, vol. 20, no. 1, pp. 126$129,2010$.

[24] D. R. Matthews, J. P. Hosker, and A. S. Rudenski, "Homeostasis model assessment: insulin resistance and $\beta$-cell function from fasting plasma glucose and insulin concentrations in man," Diabetologia, vol. 28, no. 7, pp. 412-419, 1985. 
[25] I. P. Linehan, J. Weiman, and M. Hobsley, "The 15-minute dumping provocation test," British Journal of Surgery, vol. 73, no. 10 , pp. $810-812,1986$.

[26] W. Clarke and B. Kovatchev, "Statistical tools to analyze continuous glucose monitor data," Diabetes technology \& therapeutics, vol. 11, pp. S45-S54, 2009.

[27] N. Mauras, D. Xing, R. W. Beck et al., "Prolonged nocturnal hypoglycemia is common during 12 months of continuous glucose monitoring in children and adults with type 1 diabetes," Diabetes Care, vol. 33, no. 5, pp. 1004-1008, 2010.

[28] B. Kovatchev, S. Anderson, L. Heinemann, and W. Clarke, "Comparison of the numerical and clinical accuracy of four continuous glucose monitors," Diabetes Care, vol. 31, no. 6, pp. 1160-1164, 2008.

[29] S. H. Kim, T. C. Liu, F. Abbasi et al., "Plasma glucose and insulin regulation is abnormal following gastric bypass surgery with or without neuroglycopenia," Obesity Surgery, vol. 19, no. 11, pp. 1550-1556, 2009. 


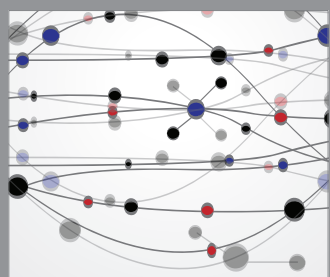

The Scientific World Journal
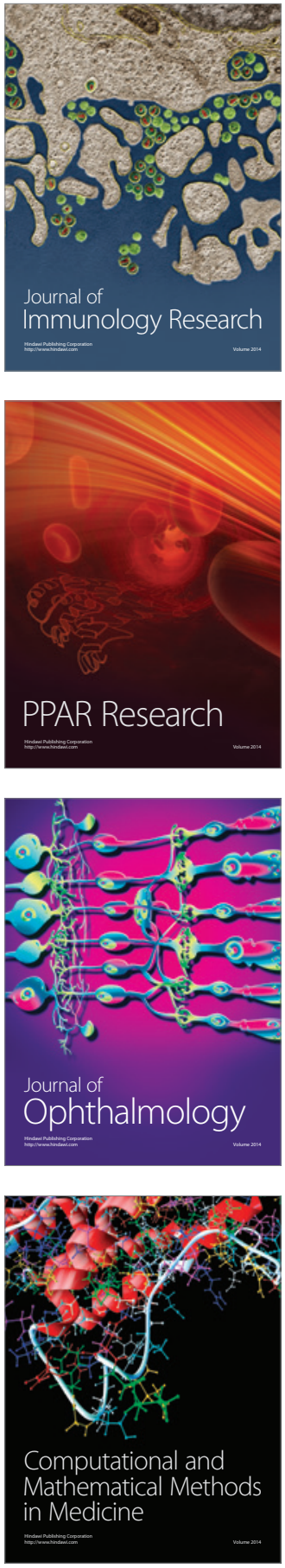

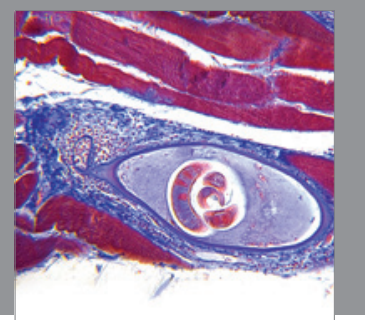

Gastroenterology

Research and Practice
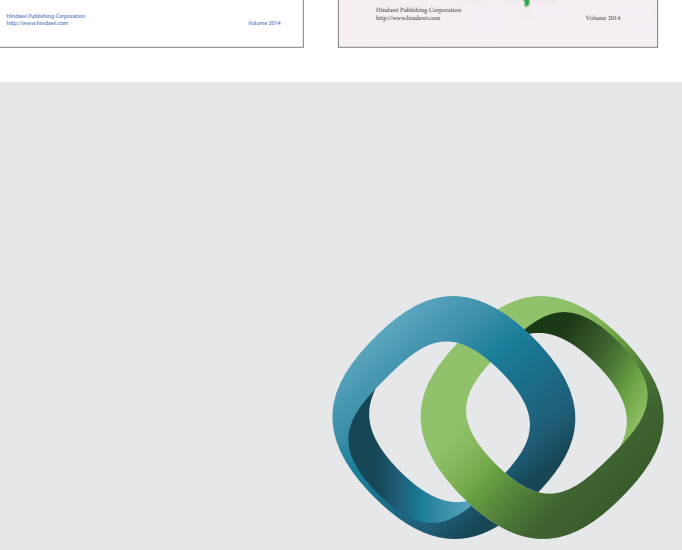

\section{Hindawi}

Submit your manuscripts at

http://www.hindawi.com
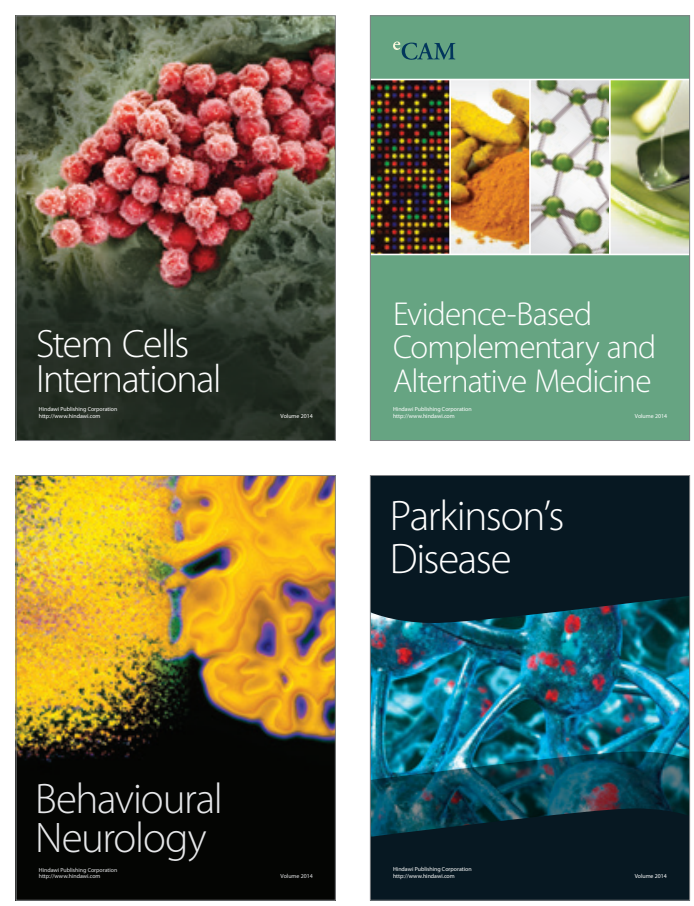

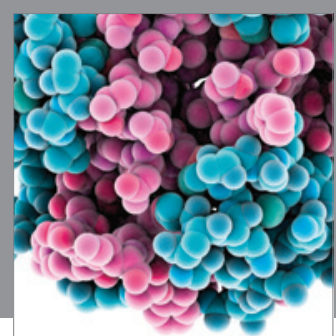

Journal of
Diabetes Research

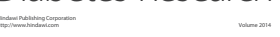

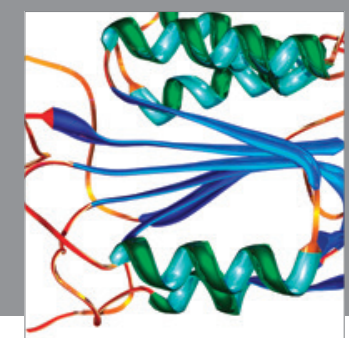

Disease Markers
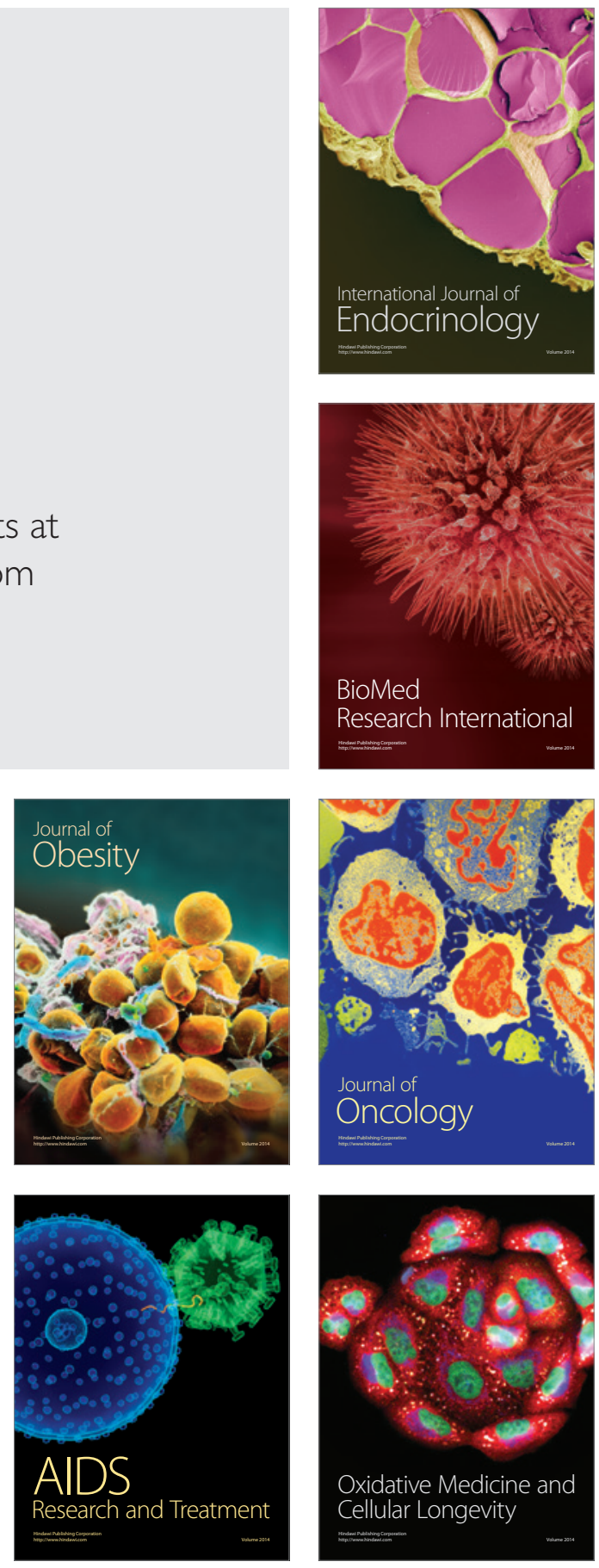